\title{
Research
}

\section{An Investigation of the Relationship between Speed-Based Verbal Reasoning Subtest of Anadolu Sak Intelligence Scale and Perceptual Speed Tests*}

\section{Anadolu-Sak Zekâ Ölçeği'nin Hıza Dayalı Sözel Analojik Muhakeme Alt Testi ile Alg1 Hizı Testleri Arasındaki İlişkisinin İncelenmesi}

\begin{abstract}
This research has two interrelated aims. The first aim of the research is to present the relationship between the Speed Based Verbal Reasoning (SBVR) subtest, which calculates reasoning speed by adjusting the Anadolu-Sak Intelligence Scale (ASIS) Verbal Reasoning (VR) subtest, and the CAS 2 intelligence scale and RIAS-2 intelligence scale speed subtests. The second aim of the research is to examine the reliability of the SBVR subtest, the item-total correlations and its relationship to the ASIS index scores. The research employed a correlational survey model and the study sample consisted of 211 students aged 6 to 7 . The reliability of the SBVR subtest was found to be high ( $\alpha$ $=.84$ ). However, we found that there is a small level relationship between SBVR and speed variables (rHDSAM-SPS $=-.16$, rHDSAM-PNM $=.18$, rHDSAM-ND $=.21$ and rHDSAM$\mathrm{SNT}=.20)$, a moderate level $(\mathrm{r}=.35)$ relationship with the memory capacity index, and a moderate level ( $\mathrm{r}=.31)$ and significant relationship with the nonverbal potential index. The research demonstrates the discrepancy between the reasoning speed and the perceptual speed.
\end{abstract}

Key Words: Anadolu-Sak Intelligence Scale, ASIS, processing speed, perceptual speed, reasoning speed

\section{Öz}

Bu çalışma birbiri ile bağlantılı iki amaca hizmet etmektedir. Araştırmanın ilk amacı, Anadolu-Sak Zekâ Ölçeği (ASİS) Sözel Analojik Muhakeme (SAM) alt testi puanlama yönteminin değiştirilmesiyle oluşturulan ve muhakeme hızını ölçen HDSAM alt testiyle CAS 2 zekâ ölçeği ve RIAS-2 zekâ ölçeğinin algı hızını ölçen alt testleri arasındaki ilişkiyi ortaya koymaktır. Araştırmanın ikinci amacı, HDSAM alt testinin güvenirliğini, madde-toplam korelasyonunu ve ASİS endeks puanlarıyla olan ilişkisini incelemektir. Araştırma ilişkisel tarama modeliyle desenlenmiş ve araştırmanın örneklemini 6 ile 7 yaş arasındaki 211 öğrenci oluşturmuştur Araştırma bulgularına göre HDSAM alt testinin güvenirliğinin yüksek $(\alpha=.84)$ olduğu görülmüştür. Diğer taraftan HDSAM ile hız değişkenleri arasında küçük (rHDSAM-SPS=-.16, rHDSAM$\mathrm{PNM}=.18$, rHDSAM-ND $=.21$ ve rHDSAM-SNT=.20), bellek kapasitesi endeksi ile orta $(\mathrm{r}=.35)$, görsel potansiyel endeksi ile orta $(r=.31)$ düzeyde anlamlı ilişki bulunmuştur. Sonuç olarak araştırma, muhakeme hızıyla algı hızının farklılaştığını literatürdeki korelasyon araştırmaları çerçevesinde desteklemektedir.

Anahtar Sözcükler: algı hızı, Anadolu-Sak zekâ ölçeği, ASİS, işleme hızı, muhakeme hız

\section{Summary}

Purpose and Significance: ASIS which is the first and only culture specific intelligence scale in Turkey. Although ASIS contains General Intelligence (GIQ), Verbal Potential (VPI), Nonverbal Potential (NPI) and Memory Capacity Indexes (MCI) (Sak et al., 2016), there is no speed index or subtest. Regarding to the aim of the research, only the ASIS VR subtest score system was organized and converted into SBVR subtest that measures the reasoning speed. It is expected that this version will bring innovation to the scale in terms of speed estimation and will offer a cognitive profile of

\footnotetext{
"The paper is based on the first author's master thesis

${ }^{1}$ Corresponding author, MS, Research assistant, Anadolu University, Faculty of Education, Eskisehir, Turkey, saadetkilicarslan@anadolu.edu.tr, ORCID: 0000-0003-0307-6740

${ }^{2}$ PhD., Research assistant, Center for Research and Practice for High Ability Education (EPTS), Anadolu University, Faculty of Education, Eskisehir, Turkey, ORCID: 0000-0001-7262-3563

${ }^{3}$ Prof., Director, Center for Research and Practice for High Ability Education (EPTS), Anadolu University, Faculty of Education, Eskisehir, Turkey, ORCID: 0000-0001-6312-5239

(c) Talent; ISSN 2717-7122 http://talentjournal.net
} 
individuals' speed performance. Whether the new scoring system measures speed or not is tested on the basis of the relationship between CAS 2 and RIAS-2 intelligence scales and speed tests.

Method: In this research, we conducted the correlational survey model. The study group of the research, which was designed with non-random convenience sampling method, consists of 211 students aged 6 to 7 in a primary school in Eskisehir, Turkey. In ASIS SBVR, the participant is expected to establish a relationship through contrast and similarity between two objects and to transfer this relationship to another object. There are two forms of scoring in HDSAM. In the first scoring type, in SBVR, participants are given 2 points for the correct answers within 0-10 seconds, 1 point for correct answers within 11-20 seconds, 0 points for incorrect answers or for the answers

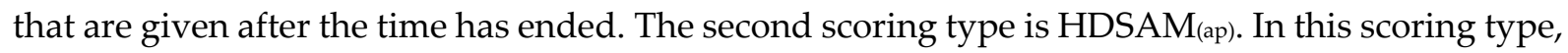
participants are given 1 point for the correct answer within 0-10 seconds, and 0 points for the correct answer within 11-20 seconds. 0 point indicates that the reasoning is not possible or cannot be done within the given time, 1 point indicates that the reasoning is done slowly, 2 points indicates that the reasoning is done faster. In addition, 4 subtests of CAS 2 intelligence scale (PCd, PNM, $\mathrm{ND}, \mathrm{RA}$ ) and 2 subtests of RIAS-2 intelligence scale (SPS, SNT) were used in the research.

Results and conclusion: This research shows that the three scoring systems of VR subtest are small level and moderate level correlated with MCI and NPI index scores. On the other hand, there is a moderate $(\mathrm{r}=.31)$ relationship between VR and SBVR tests with NPI and a moderate $(\mathrm{r}=.35)$ level relationship with MCI. Cronbach Alfa was calculated for the reliability analysis of the three scoring systems of ASIS VR (Bademci, 2011). The reliability of VR and SBVR is $\alpha=.84$, and SBVR(as) reliability is $\alpha=.83$. According to these results, the measurements obtained from the scales are high reliability (Özdamar, 2004). The relationship between item-total correlations of four items in the scale was found to be significant. These items are item $3(\mathrm{r}=.95, \mathrm{p}<.05)$, item $17(\mathrm{r}=1, \mathrm{p}<.05)$, item 18 $(\mathrm{r}=.98, \mathrm{p}<.05)$, and item $27(\mathrm{r}=.97, \mathrm{p}<.05)$. On the other hand, when the item-total correlation coefficients between SBVR(as) and VR are examined, the relationship between item-total correlations of two items are significant. These items are item $7(\mathrm{r}=.71, \mathrm{p}<.05)$ and item $17(\mathrm{r}=1, \mathrm{p}<.05)$. In between SBVR's speed tests, small level and significant relationships at $\mathrm{p}<.05$ and $\mathrm{p}<.001$ were found. In addition, SBVR shows a negative small $(\mathrm{r}=-.16)$ and significant association with the SPS subtest. SBVR with PNM, ND, and SNT subtests showed small level ( $\mathrm{rPNM}=.18, \mathrm{rND}_{\mathrm{N}}=.21$ and $\mathrm{rSNT}=.20, \mathrm{p}<.001$ ) and significant relationships. As a result, when the relationship between SBVR and speed tests were analyzed, it can be emphasized that the reasoning speed and perceptual speed differ and the research was consistent with the findings of the research conducted with speed-based tests in the literature.

\section{Giriş}

Bilişsel hız; karar verme, muhakeme, dikkat, işleme gibi bilişsel becerilere ilişkin hızı içeren çok boyutlu karmaşık bir yapı olmakla birlikte sözü geçen becerileri kapsayacak şekilde birbiri yerine de kullanılır. Bilişsel hızın bir boyutunu oluşturan işleme hızı, üst düzey bilişsel görevleri gerçekleştirme becerisini basit bilişsel görevlerin sınırlı sürede hızlı, akıcı ve doğru bir şekilde yerine getirilmesiyle tahmin etmektedir (Dehn, 2014; Schneider \& McGrew, 2018) Bununla birlikte işleme hızının nasıl ölçüleceği zekâ ölçeklerinin geliştirildiği dönemden beri tartışılmaktadır (Tulsky \& 
O’Brien, 2008). Faktör analitik yaklaşımlarda ifade edildiği üzere işleme hızı algı hızı, karar hızı gibi faktörlere dayanan çok yönlü kavramsal bir yapı olarak zekâ ölçeklerinde farklı bir yaklaşımı temsil etmektedir (Schneider \& McGrew, 2018). Örneğin zekâ ölçeklerinde ölçülen algı hızı, sembolleri tarama ve karşılaştırmayı içeren basit görevleri gerçekleştirme hızıyken (Ekstrom et al., 1976) bilişsel hızın diğer bir boyutu olarak ele alınan muhakeme hızı anlama, ilişki kurma gibi üst düzey bilişsel becerilerin zaman baskısı altında işe koşulmasıdır (Gardner, 1993; Wilhelm \& Schulze, 2002). Dolayısıyla bilişsel hızın çok sayıda bilişsel becerinin etkisinde olması hız ölçümünü karmaşıklaştırmakta ve alanyazında ikiliğe neden olmaktadır.

Hız ölçümü için en iyi yöntemin hangisi olduğu tartışmalıdır. Ancak bilişin birden çok boyutunu ölçen ve zekâya ilişkin güçlü bir yordayıcı olan zekâ ölçeklerinde hız değerlendirilmektedir (Wechsler, 1991). Bu zekâ ölçeklerinde işleme hızı ve algı hızı basit bilişsel görevlerle ölçülme eğilimindeyken daha karmaşık bilişsel görevler muhakeme hızıyla ilişkilendirilmektedir. Bunun yanı sıra bu değişkenler arasındaki ilişkinin tahmini için basit hız prosedürleriyle birlikte muhakeme görevleri de kullanılmaktadır (Wilhelm \& Schulze, 2002).

İfade edildiği gibi hız ölçümünün zekâ ölçeklerinde bilişsel profile ilişkin yeni bir bakış açısı sunmasından hareketle Anadolu-Sak Zekâ Ölçeği'ndeki (ASİS) Sözel Analojik Muhakeme (SAM) alt testinin puanlama sistemi düzenlenmiş ve hız ölçümüne uygun hale getirilerek Hıza Dayalı SAM (HDSAM) olarak adlandırılmıştır. HDSAM alt testinin kullanılmasının iki amacı bulunmaktadır. İlk ve temel amacı HDSAM ile ölçülen muhakeme hızı ve Bilişsel Değerlendirme Sistemi Ölçeği2'deki (CAS 2) Planlanmış Kodlar (PCd), Planlanmış Sayı Eşleme (PNM), Sayı Bulma (ND), Algısal Dikkat (RA) ve Reynolds Bilişsel Değerlendirme Öçeği-2'deki (RIAS-2) Hıza Dayalı İsimlendirme (SNT), Hıza Dayalı Resim Arama (SPS) alt testleriyle ölçülen algı hızı arasındaki ilişkinin incelenmesidir. İkinci amacı HDSAM'ın güvenirliğini, madde-toplam korelasyonunu ve ASİS endeks puanlarıyla olan ilişkisini araştırmaktır.

\section{Hızın Ölçümü}

Alanyazında çok sayıda araştırmanın yapıldığı işleme hızı, zekâ ölçeklerindeki çeşitli bilişsel görevlerle bilişsel performansın akıcıllı̆ını ve değişkenliğini öngörür (Kail \& Salthouse, 1994). Buna rağmen bazı araştırmacılar hızın, bireye özgü karar verme ve dikkat becerileriyle ilişkili olan deneyim, öğrenme kapasitesi (Goldhammer \& Entink, 2011) ve motivasyon (Kail, 2008) gibi değişkenlerin etkisi altında olduğu için psikometrik araçlarla ölçülemeyeceğini ileri sürmektedir. Bu savı destekleyen bazı araştırmacıların önerdiği üzere sözü edilen bu değişkenler, hızı ölçmeyi güçleştirirken (Ball \& Vance, 2008; Kyllonen \& Zu, 2016) bazı araştırmacılar bu değişkenlerin göz ardı edilerek işleme hızının basit görevlerle ölçülebileceğini iddia etmektedir (Deluca \& Chiaravalloti, 2004; Fry \& Hale, 2000). Alanyazında hız ölçümüne ilişkin karşıt görüşler olsa da hız görevinin niteliği hız ölçümünde önemli bir belirleyicidir. Örneğin genellikle işleme hızı görevleri basit düzeyde olduğu için bireysel farklılıkların yanıtlar üzerinde etkisi görece azdır (Schubert et al., 2015). Dolayısıyla bireysel farklılıkların birlikte ya da ayrı ayrı işe koşulması işleme hızına ilişkin geçerli kanitların elde edilmesini sağlar.

Mevcut yaklaşımlar bireylerin akademik performansının, okuma-yazma becerisinin ve matematik 
yeteneğinin önemli bir yordayıcısı olduğu için işleme hızının ölçülmesi gerektiğini savunmaktadır (Floyd et al., 2008; Kail, 2008; Moll et al., 2016; Vukovic \& Siegel, 2010). Daha geniş bir bakış açısıyla bireylerin öğrenme güçlüğü, özgül öğrenme bozuklukları, dikkat eksikliği ve hiperaktivite bozukluğu gibi bilişsel işleyişe ilişkin sorunların tanılanması ve değerlendirilmesi için de hızın ölçülmesi gerektiği iddia edilmektedir (Naglieri et al., 2014; Wechsler, 2014). Bu gerekçeler ve yaklaşımlar çerçevesinde zekâ ölçeklerindeki işleme hızı ölçümünün bireylerin üst düzey bilişsel performansının yordayıcısı olması ve uygun eğitsel müdahalelerin uygulanması açsısından önem taşıdığı düşünülmektedir.

\section{Zekâ Ölçeklerinde Hız Ölçümü}

Alanyazında CAS-2, RIAS-2, Woodcock-Johnson Bilişsel Yetenekler Testi-IV (WJ-COG IV), Wechsler Zekâ Ölçekleri (WISC), Wechsler Yetişkinler için Zekâ Ölçeği-IV (WAIS-IV) gibi zekâ ölçekleriyle hız değerlendirilmektedir. Öte yandan bu ölçeklerin algı hızını, dikkati, psikomotor hızı, işleme hızını ölçtüğü rapor edilmektedir (Naglieri et al., 2014; Reynolds \& Kamphaus, 2015; Schrank et al., 2014; Wechsler, 2014). Bunun yanı sıra zekâ ölçeklerine ait hız testleri korelasyon çalışmaları bu testlerin geçerliklerine ilişkin kanıt sunduğu için önemlidir. Bu zekâ ölçeklerinden WISC-V'in işleme hız endeksiyle Kaufman Çocuklar için Değerlendirme Bataryası-II (KABC-II) zihinsel işleme endeksi arasında küçük (r=.04) (Flanagan \& Alfonso, 2017), WJ-IV COG ile WAIS-IV işleme hızı alt testleri arasında orta ( $\mathrm{r}=.44)$, WJ-IV COG ile WISC-IV işleme hızı alt testleri arasında orta $(\mathrm{r}=.55)$ düzeyde ilişki bulunmuştur (Schrank et al., 2014). Bir diğer zekâ ölçeği RIAS-2'de SPS alt testiyle WISC-IV sembol arama alt testi (SS) arasında küçük (r=-.06), SPS ile WISC-IV çiz çıkart testi (CA) arasında küçük (r=-.17) düzeyde ilişki rapor edilmiştir. RIAS-2 SNT ile WISC-IV SS alt testleri arasında küçük (r=.25), SPS ile WISC-IV CA alt testleri arasında küçük (r=.29), SNT ile WISC-IV şifre alt testi (CD) arasında küçük (r=.14), SPS ile WISC-IV CD alt testi arasında küçük (r=.08) düzeyde ilişki bulunmuştur (Reynolds \& Kamphaus, 2015). Bu çalışmalar incelendiğinde adı geçen hız alt testlerinin birbiriyle nispeten uyum göstermedikleri vurgulanabilir.

RIAS-2, WISC-IV, WISC-V, WJ-COG zekâ ölçeklerinin hız alt testleriyle arasındaki ilişkiler üzerinde test görevlerinin, madde tamamlama sürelerinin, bonus puanların ve puanlama sistemlerinin farklılık göstermesi büyük oranda belirleyici olabilir. Sonuç olarak zekâ ölçeklerinde hız, görsel arama, dikkat, ifade edici dil gibi farklı görevlerin işe koşulmasıyla ölçülür. Ancak temelde hız testlerinin ortak amacı, sınırlı süre içinde görevlerin tamamlanarak bireylerin bilişsel hız performanslarını ölçmek olduğu söylenebilir.

Alanyazında genellikle algı hızına (CAS 2, WJ-IV COG, RIAS-2) ve işleme hızına yönelik testlerin (WISC-IV, WISC-V, RIAS-2, WJ-IV COG) bulunduğu dikkati çekmektedir. Öte yandan Schneider \& McGrew (2018) muhakeme hızı testlerinin sınırlı sayıda olduğunu belirtmektedir. Alanyazında muhakeme hızı testlerine ihtiyaç duyulması, muhakeme hızı ölçümünün bireylerin üst düzey bilişsel becerilerini ne düzeyde kullanabildiğinin tespit edilmesi açısından önem taşıması (Wilhelm \& Schulze, 2002) gibi gerekçeler muhakeme hızı ölçümünü gerekli kılmaktadır. Ayrıca, hız ölçümünde ölçme araçlarının kültüre uygunluğu, performansa ilişkin sonuçların geçerliğini etkilemektedir (Ford, 2004). Dolayısıyla kültüre uygun bir ölçekle hız performansına ilişkin geçerli ve güvenilir sonuçlar ortaya çıarabilir. 
Araştırmada kültüre uygunluk kriteri göz önünde bulundurulduğunda ASİS'in kültür kriterini karşılayan tek zekâ ölçeği olduğu görülmektedir. Ayrıca ASİS'te hıza ilişkin endeks ya da alt test bulunmamaktadır. Ancak yukarıda ifade edilen gerekçelerden hareketle muhakeme hızının ölçülmesi gerekli görülmektedir. Bu nedenle araştırmanın amacıyla ilişkili olarak ASİS SAM alt testinin sadece puanlama sistemi düzenlenerek muhakeme hızını ölçen HDSAM alt testine dönüştürülmüştür. Bu düzenlemenin ölçeğe, hızın ölçülmesi noktasında yenilik getireceği ve bireylerin bilişsel hız performansını ölçeceği varsayılmaktadır. Oluşturulan puanlama sisteminin hızı ölçüp ölçmediği CAS 2 ve RIAS-2 zekâ ölçeklerinin hız testleriyle arasındaki ilişki temelinde sınanmaktadır.

\section{Yöntem}

\section{Çalışma Grubu}

Seçkisiz olmayan kolay ulaşılabilir örnekleme yöntemiyle desenlenen araştırmanın çalışma grubunu, Eskişehir İl Milli Eğitim Müdürlüğü ve Anadolu Üniversitesi Üstün Yetenekliler Eğitimi Araştırma ve Uygulama Merkezi (ÜYEP) arasında gerçekleştirilen protokol kapsamında yer alan bir ilkokuldaki altı ile yedi yaş düzeyinde 211 öğrenci oluşturmaktadır. Çalışma grubunda $117 \mathrm{kız}$, 94 erkek öğrenci bulunurken bu öğrencilerin 182'si altı yaş, 29'u yedi yaş düzeyindedir.

\section{Veri Toplama Araçları}

Araştırmanın bu bölümünde ASIS, HDSAM, CAS 2 PCd, PNM, ND, RA, RIAS-2 SPS, SNT araçlarına ilişkin bilgiler sunulmuştur.

Anadolu-Sak Zekâ Ölçeği (ASİS). ASİS' in kuramsal yapısı Cattell-Horn-Carroll modeline, alt testlerin kuramsal yapısı Luria'nın nöropsikolojik modeli ve Baddeley'in bellek modeline dayanmaktadır. 4 ile 12 yaş arasındaki çocukların zekâ düzeyini belirlemek amacıyla geliştirilen ASİS'te yedi alt testten elde edilen endeks puanları bulunmaktadır. Genel zekâ endeksi (GIQ) genel zihinsel işleyişin değerlendirilmesinde kullanılmaktadır. Sözel potansiyel endeksi (SPE), kristalize zekâyı ölçen sözcükler ve anlamlar (SAN) ile akıcı ve kristalize zekâyı ölçen sözel analojik muhakeme (SAM) alt testlerinden oluşmaktadır. Görsel potansiyel endeksi (GPE) akıcı zekâyı ölçen görsel analojik muhakeme (GAM) ve görsel-uzamsal işleme bileşenlerini temsil eden görsel algısal esneklik (GES) alt testlerinden oluşur. Görsel ardıl bellek (GAB), sözel kısa süreli bellek (SKB) ve görsel eş zamanlı bellek (GEB) alt testlerinden oluşan bellek kapasitesi endeksi (BKE) çalışma belleğin performansını ölçmektedir (Sak vd., 2016).

ASIS'in Güvenirlik ve Geçerliği. Bir ölçekten elde edilen bulguların doğru bir şekilde yorumlanabilmesi için ölçeğin geçerli ve güvenirliğinin yüksek düzeyde olması gerekmektedir (Karakoç ve Dönmez, 2014). Bu bağlamda ASİS'in ölçüt geçerliğinin yüksek düzeyde olduğu, güvenirlik kanıtları incelendiğinde alt testlerin ve endeks puanları güvenirliklerinin .81-.99 arasında, SAM'ın güvenirliğinin ise .97 olduğu saptanmıştır (Sak vd., 2016). Yapılan çalışmalar ASİS'in geçerli ve güvenirliği yüksek bir ölçme aracı olduğunu göstermektedir.

ASIS Hıza Dayalı Sözel Analojik Muhakeme Alt Testi (HDSAM). Analoji yapısı “A:B ise C: ?" şeklinde sunulan alt testte iki nesne arasında zıtlık, benzerlik aracılığıyla ilişki kurulması ve bu 
ilişkinin başka bir nesneye aktarılması istenir. Bu analojiler aracılığıyla benzetim, muhakeme kurma ve problem çözme becerisi ölçülmektedir. Bununla birlikte katılımcılar, üç maddeyi art arda yanlış cevapladığında alt test sonlandırılmaktadır. Alt testin puanlaması incelendiğinde SAM'ın orijinal puanlamasında 20 saniye içinde verilen doğru cevaplar için 1, yanlış cevap ve süre bittikten sonra verilen cevaplar için 0 puan verilmektedir. Bu çalışmada Hıza Dayalı SAM (HDSAM) olarak adlandırılan puanlama sisteminde 0-10 saniye içindeki doğru cevaplar için 2, 11-20 saniye içindeki doğru cevaplar için 1, yanlış ya da süre bittikten sonra verilen cevaplar için 0 puan verilmiştir. Ayrıca HDSAM' da alternatif puanlama kullanılmış ve "HDSAM(ap)" şeklinde adlandırılmıştır. Bu sistemde 0-10 saniye içindeki doğru cevaba 1, 11-20 saniye içindeki doğru cevaba 0 puan verilmiştir. Bununla birlikte 0 puan muhakemenin yapılamadığının ya da verilen süre içinde yapılamadığının, 1 puan muhakemenin yavaş yapıldığının, 2 puan muhakemenin hızlı yapıldığının göstergesidir. Tablo 1'de puanlama sistemlerine ilişkin puan değerleri verilmiştir.

Tablo 1. ASİS SAM, HDSAM ve HDSAM(ap) Puan Değerleri

\begin{tabular}{ccc}
\hline Puanlama Sistemi & Süre & Puan \\
\hline \multirow{2}{*}{ SAM } & 0 -20 saniye & 1 \\
& 21 saniye üzeri & 0 \\
\hline \multirow{2}{*}{ HDSAM } & $0-10$ saniye & 2 \\
& $11-20$ saniye & 1 \\
& 21 saniye üzeri & 0 \\
\hline \multirow{2}{*}{$\operatorname{HDSAM}_{(\text {ap) }}$} & 0 -10 saniye & 1 \\
& 11 saniye üzeri & 0 \\
\hline
\end{tabular}

Tablo 1'de puanlama sistemleri incelendiğinde ilk 10 saniye içinde testten alınan en yüksek puan HDSAM puanlama türünden elde edilmektedir.

CAS 2 PCd, PNM, ND, RA Alt Testlerinin Güvenirlik ve Geçerliği. CAS 2 PCd alt testinde katılımcıdan harf-kod ikililerini 60 saniye içinde hızlı bir şekilde yazması, PNM alt testinde 180 saniye içinde her satırdaki aynı sayı çiftlerini hızlı bir şekilde işaret etmesi istenir. ND alt testinde 60 saniye içinde hedeflenen sayıları diğer sayılar arasından hızlı bir şekilde bulup işaret etmesi, RA alt testinde 45 saniye içinde hızlı bir şekilde bir satırda aynı olan resimleri işaret etmesi istenir. Testlerde odaklanmış dikkat, seçici dikkat, sürekli dikkat, bölünmüş dikkatle birlikte hız ölçülür (Naglieri et al., 2014). CAS 2 PCd, PNM, ND ve RA alt testlerinin güvenirlikleri .80 ile .88 arasinda, test tekrar test .75 ile .86 , puanlayıcılar arası güvenirlikleri ise .99 olarak hesaplanmıştır.

RIAS-2 SNT, SPS Alt Testleri Güvenirlik ve Geçerliği. RIAS-2 SNT alt testinde katılımc1dan 60 saniye içinde hızlı bir şekilde sayfada yer alan nesnelerin isimlerini sırasıyla söylemesi, SPS alt testinde katılımcıya hedef nesne gösterildikten sonra katılımcıdan 300 saniye içinde diğer nesneler arasından üç adet hedef nesneyi hızlı bir şekilde işaret etmesi istenmektedir. Bu alt testlerde işleme hızı, algı hızı, dil becerisi, dikkat ve basit görsel algı ölçülmektedir (Reynolds \& Kamphaus, 2015). RIAS-2 hız testlerinin güvenirlik çalışması kapsamında iç tutarlık .98 ile .99, test tekrar test hıza dayalı isimlendirme için .85, hıza dayalı resim arama için .72 ve puanlayıcılar arası güvenirlik 1 olarak raporlanmıştır. 


\section{Süreç}

Araştırmada veriler iki aşamada toplanmıştır. İlk aşamada ASİS verileri, 2018-2019 eğitim öğretim yılında ASİS uygulama yeterliğine sahip dört uygulayıcı ve bir araştırmacıyla birlikte araştırmanın yapıldığı okulda test odalarında toplanmıştır. Bu veriler toplanmadan önce uygulayıcılara, yanıtların HDSAM alt testi süre-puan kriterine göre kaydedilmesi konusunda eğitim verilmiştir. İkinci aşamada CAS 2 ve RIAS-2 alt testlerinin verilerini bir uygulayıcı araştırma okuluna ait test odasında toplamıştır. Hıza dayalı testlerin tamamında süre kayıtları için kronometre kullanılmıştır. Araştırmada psikomotor becerilerin test puanlarına etkisini en aza indirmek için RIAS-2 SPS alt testinde uygulayıcı, katılımcının cevaplarını işaretlemiştir. CAS-2 PNM, ND, RA alt testlerinde ise yanıtların olduğu bir form oluşturulmuş ve katılımcının yanıtları uygulayıcı tarafından bu formlara kaydedilmiştir.

\section{Verilerin Analizi}

Verilerin analizinde ölçeklerden alınan ham puanlar kullanılmış olup SAM, HDSAM, HDSAM(ap) verileri ayrı ayrı kodlanmıştır. Verilerin en düşük, en yüksek, ortalama $(\bar{X})$ ve standart sapma (SS) değerleri için betimsel analiz yapılarak verilere ait çarpıklık ve basıklık değerleri .14 ile 1.98 arasında hesaplanmış ve korelasyon analizi için normallik ön koşulu sağlanmıştır (George \& Mallery, 2010). Korelasyon analizinde Pearson momentler çarpımı (Pallant, 2005), güvenirlik analizinde Cronbach Alfa hesaplanmış (Çakmur, 2012) ve aynı örneklem grubuna ait madde-toplam korelasyonları arasındaki farkın anlamlılı̆̆ı incelenmiştir (Diedenhofen \& Musch, 2015).

\section{Bulgu ve Yorumlar}

Araştırmanın amacı doğrultusunda ASİS SAM ile HDSAM ve HDSAM(ap) arasındaki ilişki incelenmiştir ve bu ilişkiye ait bulgular Tablo 2' de verilmiştir.

Tablo 2. ASİS SAM ile HDSAM ve HDSAM(ap) Arasındaki İlişki

\begin{tabular}{lcc}
\hline $\mathbf{N}=\mathbf{2 1 1}$ & SAM & HDSAM \\
\hline HDSAM & $.98^{* *}$ & - \\
$\operatorname{HDSAM}_{(\text {ap })}$ & $.91^{* *}$ & $.97^{* *}$ \\
\hline
\end{tabular}

Tablo 2 incelendiğinde değişkenler arasında Cohen'e (1988) göre büyük düzeyde anlamlı ilişkiler bulunmuştur. Aynı zamanda HDSAM ile SAM arasında belirleme katsayısı $R^{2}=.96$ 'dır. Buna göre HDSAM'ın toplam varyansının \%96'sı hıza dayalı olmayan SAM tarafından açıklanır. SAM ile $\operatorname{HDSAM}_{(\text {(ap) }}$ arasında belirleme katsayısı $R^{2}=.82^{\prime}$ dir. Buna göre $\operatorname{HDSAM}_{(\mathrm{ap})}{ }^{\prime} 1 \mathrm{n}$ toplam varyansının \%82'si hıza dayalı olmayan SAM tarafından açıklanmaktadır. Değişkenlerin varyansları büyük oranda birbirini açıklamaktadır.

ASİS endeks puanları ile SAM, HDSAM ve $\operatorname{HDSAM}_{(\mathrm{ap})}$ arasındaki ilişki Pearson korelasyon analiziyle incelenmiştir. Tablo 3'te SAM, HDSAM, HDSAM(ap) ile ASİS endeks puanları arasındaki korelasyon bulguları verilmiştir.

Tablo 3'te SAM, HDSAM ve HD SAM(ap)' 1 n BKE ve GPE endeks puanlarıyla arasında küçük ve 
orta düzeyde anlamlı ilişkilerin olduğu dikkati çekmektedir. Bununla birlikte puanlama sistemi farklılığına rağmen bazı değişkenler arasında aynı düzeyde ilişkiler bulunmuştur. Bunlar GPE ile SAM ve HDSAM arasında orta düzeyde ( $\mathrm{r}=.31)$, BKE ile SAM ve HDSAM arasında orta düzeyde $(\mathrm{r}=.35)$ anlamlı ilişki olarak hesaplanmıştır.

Tablo 3. ASİS SAM, HDSAM ve HDSAM(ap) ile ASİS Endeks Puanları Arasındaki İlişki

\begin{tabular}{llc}
\hline & & ASİS Endeksleri \\
\hline $\mathbf{N}=\mathbf{2 1 1}$ & GPE & BKE \\
\hline SAM & $.31^{* *}$ & $.35^{* *}$ \\
HDSAM & $.31^{* *}$ & $.35^{* *}$ \\
HD SAM(ap) & $.29^{* *}$ & $.33^{* *}$ \\
\hline
\end{tabular}

ASIS SAM'ın üç puanlama sisteminin güvenirlik analizleri için Cronbach Alfa $(\alpha)$ hesaplanmıştır (Bademci, 2011). SAM ve HDSAM'ın güvenirliği $\alpha=.84, \operatorname{HDSAM}_{\text {(ap) }}$ güvenirliği $\alpha=.83^{\prime}$ tür. Bu durumda ölçeklerden elde edilen ölçümler yüksek düzeyde güvenilirdir (Özdamar, 2004). SAM, HDSAM ve HDSAM(ap) ${ }^{\prime}$ nın madde istatistikleri Tablo 4 ve Tablo 5'te sunulmuştur.

Tablo 4. SAM ile HDSAM ve SAM ile HDSAM(ap) Madde-Toplam Korelasyonları Arasındaki Farklılaşma

\begin{tabular}{lcccccc}
\hline & \multicolumn{3}{c}{ SAM ile HDSAM } & \multicolumn{3}{c}{ SAM ile HDSAM(ap) } \\
\hline Madde No & $\mathbf{r}$ & $\mathbf{Z}$ & $\boldsymbol{p}$ & $\mathbf{r}$ & $\mathbf{Z}$ & $p$ \\
\hline 1 & .91 & .00 & 1.00 & .73 & 0.37 & 0.70 \\
2 & .96 & 1.31 & 0.19 & .86 & -1.65 & 0.09 \\
3 & .95 & 2.18 & 0.02 & .84 & -1.94 & 0.05 \\
4 & .96 & 0.46 & 0.63 & .86 & -0.24 & 0.80 \\
5 & .98 & .00 & 1.00 & .92 & 0.00 & 1.00 \\
6 & .96 & -1.49 & 0.13 & .85 & -1.03 & 0.30 \\
7 & .92 & 0.76 & 0.44 & .71 & 2.04 & 0.04 \\
8 & .96 & -0.56 & 0.57 & .86 & 0.00 & 1.00 \\
9 & .96 & -0.50 & 0.61 & .86 & -0.26 & 0.78 \\
10 & .97 & -1.03 & 0.29 & .89 & -0.60 & 0.54 \\
11 & .97 & 0.00 & 1.00 & .90 & 0.56 & 0.57 \\
12 & .96 & 0.97 & 0.33 & .93 & 1.24 & 0.21 \\
13 & .96 & -1.34 & 0.18 & .85 & -0.24 & 0.80 \\
14 & .98 & -1.04 & 0.29 & .93 & 0.00 & 1.00 \\
15 & .98 & 1.77 & 0.07 & .92 & 1.89 & 0.05 \\
16 & .96 & -0.89 & 0.37 & .82 & 0.69 & 0.48 \\
17 & 1 & -2.06 & 0.03 & 1 & 2.28 & 0.02 \\
18 & .98 & 2.46 & 0.01 & .94 & & \\
19 & .98 & 1.42 & 0.15 & .94 & 0.81 & 0.41 \\
20 & .96 & 1.17 & 0.24 & .84 & 1.67 & 0.09 \\
21 & .97 & 0.65 & 0.51 & .89 & 1.34 & 0.17 \\
22 & .98 & 1.53 & 0.12 & .93 & 0.77 & 0.43 \\
23 & 1 & -1.28 & 0.19 & 1 & -0.73 & 0.46 \\
24 & .97 & 1.84 & 0.06 & .91 & 1.42 & 0.15 \\
25 & 1 & -0.74 & 0.45 & 1 & -0.69 & 0.48 \\
26 & 1 & -0.63 & 0.52 & 1 & -0.36 & 0.71 \\
27 & .97 & 2.31 & 0.02 & .89 & 1.55 & 0.11 \\
28 & .98 & 1.53 & 0.12 & .92 & 1.15 & 0.24 \\
\hline & & & & & & \\
\hline
\end{tabular}


Tablo 4' te SAM ile HDSAM ve SAM ile HDSAM(ap) madde-toplam korelasyonları arasındaki farklılığa ilişkin bulgular bulunmaktadır. HDSAM ile SAM'daki madde 3 ( $\mathrm{r}=.95, \mathrm{p}<.05)$, madde 17 ( $\mathrm{r}=1$, $\mathrm{p}<.05)$, madde $18(\mathrm{r}=.98, \mathrm{p}<.05)$ ve madde $27(\mathrm{r}=.97, \mathrm{p}<.05)$ madde-toplam korelasyonları arasındaki ilişki anlamlıdır. Öte yandan $\operatorname{HDSAM}_{(\mathrm{ap})}$ ile SAM arasındaki madde-toplam korelasyon katsayılarının $\mathrm{Z}$ ve $\mathrm{p}$ dönüşümlerine göre madde $7(\mathrm{r}=.71, \mathrm{p}<.05)$ ve madde $17(\mathrm{r}=1, \mathrm{p}<.05)$ madde-toplam korelasyonları arasındaki ilişki anlamlıdır.

Tablo 5. ASİ SAM, HDSAM, HDSAM(ap) Madde İstatistikleri

\begin{tabular}{|c|c|c|c|c|c|c|c|c|c|c|c|c|}
\hline \multirow{3}{*}{$\begin{array}{l} \\
\text { Madde } \\
\text { No. }\end{array}$} & \multirow[b]{3}{*}{$\bar{X}$} & \multirow{2}{*}{\multicolumn{4}{|c|}{ SAM (1-0) }} & & & & & & & \\
\hline & & & & & & \multicolumn{4}{|c|}{ 0) } & \multicolumn{3}{|c|}{$\operatorname{HDSAM}_{\text {(ap) }}(1-0)$} \\
\hline & & SS & DMTK & $\mathrm{MÇ} \alpha$ & $\bar{X}$ & SS & MTK & $\mathrm{MÇ} \alpha$ & $\bar{X}$ & SS & DMTK & $\mathrm{MÇ} \alpha$ \\
\hline 1 & .82 & .38 & .26 & .84 & 1.53 & .78 & .26 & .84 & .71 & .45 & .24 & .83 \\
\hline 2 & .74 & .43 & .18 & .85 & 1.43 & .87 & .21 & .85 & .69 & .46 & .25 & .83 \\
\hline 3 & .85 & .36 & .31 & .84 & 1.65 & .73 & .36 & .84 & .80 & .40 & .39 & .83 \\
\hline 4 & .77 & .42 & .36 & .84 & 1.49 & .84 & .37 & .84 & .72 & .45 & .37 & .83 \\
\hline 5 & .50 & .50 & .39 & .84 & .97 & .98 & .39 & .84 & .46 & .50 & .39 & .83 \\
\hline 6 & .56 & .49 & .40 & .84 & 1.05 & .96 & .43 & .84 & .49 & .50 & .44 & .83 \\
\hline 7 & .56 & .49 & .49 & .84 & .96 & .91 & .47 & .84 & .40 & .49 & .39 & .83 \\
\hline 8 & .75 & .43 & .55 & .83 & 1.44 & .86 & .56 & .83 & .69 & .46 & .55 & .82 \\
\hline 9 & .42 & .49 & .47 & .84 & .77 & .93 & .48 & .84 & .35 & .47 & .48 & .83 \\
\hline 10 & .38 & .48 & .51 & .83 & .72 & .93 & .53 & .83 & .33 & .47 & .53 & .82 \\
\hline 11 & .40 & .49 & .44 & .84 & .75 & .94 & .44 & .84 & .35 & .47 & .42 & .83 \\
\hline 12 & .12 & .32 & .44 & .84 & .22 & .61 & .42 & .84 & .10 & .30 & .40 & .83 \\
\hline 13 & .29 & .45 & .46 & .84 & .52 & .84 & .49 & .84 & .23 & .42 & .47 & .83 \\
\hline 14 & .08 & .26 & .45 & .84 & .14 & .50 & .47 & .84 & .07 & .24 & .45 & .83 \\
\hline 15 & .10 & .30 & .50 & .84 & .19 & .58 & .47 & .84 & .09 & .28 & .44 & .83 \\
\hline 16 & .06 & .24 & .47 & .84 & .10 & .42 & .49 & .84 & .04 & .20 & .43 & .83 \\
\hline 17 & .08 & .27 & .50 & .84 & .16 & .54 & .53 & .84 & .08 & .27 & .53 & .83 \\
\hline 18 & .04 & .20 & .40 & .84 & .08 & .38 & .36 & .84 & .04 & .19 & .34 & .83 \\
\hline 19 & .04 & .20 & .55 & .84 & .08 & .38 & .53 & .84 & .04 & .19 & .53 & .83 \\
\hline 20 & .05 & .22 & .55 & .84 & .09 & .39 & .53 & .84 & .04 & .19 & .49 & .83 \\
\hline 21 & .05 & .21 & .60 & .84 & .09 & .39 & .59 & .84 & .04 & .19 & .56 & .83 \\
\hline 22 & .04 & .19 & .53 & .84 & .07 & .36 & .51 & .84 & .03 & .18 & .51 & .83 \\
\hline 23 & .02 & .13 & .37 & .84 & .04 & .27 & .39 & .84 & .02 & .13 & .39 & .83 \\
\hline 24 & .03 & .16 & .49 & .84 & .05 & .31 & .46 & .84 & .02 & .15 & .45 & .83 \\
\hline 25 & .00 & .06 & .22 & .84 & .01 & .13 & .23 & .84 & .00 & .06 & .24 & .83 \\
\hline 26 & .01 & .11 & .34 & .84 & .03 & .23 & .35 & .84 & .01 & .11 & .35 & .83 \\
\hline 27 & .02 & .15 & .43 & .84 & .04 & .28 & .39 & .84 & .02 & .13 & .38 & .83 \\
\hline 28 & .03 & .18 & .53 & .84 & .06 & .33 & .1 & .84 & .03 & .16 & .50 & .83 \\
\hline MTK $_{\text {ort }}$ & & & .43 & & & & .45 & & & & .42 & \\
\hline
\end{tabular}

DMTK: Düzeltilmiş madde toplam korelasyonu. MÇ $\alpha=$ Madde çıarıldığında Cronbach's Alfa. MTK: Madde toplam korelasyon, MTKort: Madde toplam korelasyon ortalama

Tablo 5'te SAM, HDSAM ve HD SAM(ap)'a ait maddelerin düzeltilmiş madde-toplam korelasyonları incelendiğinde alt test maddelerinin aynı amaca hizmet ettiği görülmektedir (Crocker \& Algina, 2006). Sadece SAM puanlama sisteminde bir maddenin düzeltilmiş madde toplam korelasyonu .20'den küçüktür. Bu madde ölçekten çıkarıldığında SAM'ın $\alpha$ değeri .85 olsa da bu işlem, 
ölçeğin güvenirlik düzeyini büyük oranda etkilememektedir. Son olarak HDSAM'ın madde-toplam korelasyon ortalamasının, SAM ve $\operatorname{HDSAM}_{(\mathrm{ap})}$ 'nın madde-toplam korelasyon ortalamasına göre daha yüksek düzeyde olduğu bulunmuştur.

SAM, HDSAM ve HDSAM(ap)' 1 n CAS 2 ölçeği ile PCd, PNM, ND, RA, RIAS-2 SNT ve SPS testleri arasındaki ilişkinin incelenmesine ilişkin bulgular Tablo 6' da verilmiştir.

Tablo 6. SAM, HDSAM, HDSAM(ap) ile CAS 2 PCd, PNM, ND, RA, RIAS-2 SNT, SPS Alt Testleri Arasındaki İlişki

\begin{tabular}{llcccccccc}
\hline Ölçek & Alt Testler & SAM & HDSAM & HDSAM(ap) & PCd & PNM & ND & RA & SNT \\
\hline & PCd & $.15^{*}$ & $.16^{*}$ & $.15^{*}$ & - & & & & \\
CAS 2 & PNM & $.16^{*}$ & $.18^{* *}$ & $.19^{* *}$ & $.48^{* *}$ & - & & & \\
& ND & $.19^{* *}$ & $.21^{* *}$ & $.22^{* *}$ & $.52^{* *}$ & $.53^{* *}$ & - & & \\
& RA & $.16^{*}$ & $.16^{*}$ & $.15^{*}$ & $.54^{* *}$ & $.59^{* *}$ & $.54^{* *}$ & - & \\
\hline RIAS-2 & SNT & $.18^{* *}$ & $.20^{* *}$ & $.21^{* *}$ & $.39^{* *}$ & $.34^{* *}$ & $.51^{* *}$ & $.40^{* *}$ & - \\
& SPS & $-.17^{*}$ & $-.16^{*}$ & $-.15^{*}$ & $-.23^{* *}$ & $-.31^{* *}$ & $-.34^{* *}$ & $-.28^{* *}$ & $-.21^{* *}$ \\
\hline
\end{tabular}

${ }^{* *} \mathrm{p}<.001,{ }^{*} \mathrm{p}<.05$

SAM: Sözel analojik muhakeme, HDSAM: Hıza dayalı sözel analojik muhakeme, PCd: Planlanmış kodlar, PNM: Planlanmış sayı eşleme, ND: Sayı bulma, RA: Algısal dikkat, SNT: Hıza dayalı isimlendirme, SPS: Hiza dayalı resim arama.

Tablo 6 incelendiğinde SAM'a ait farklı puanlamalara rağmen bu değişkenlerin diğer ölçeklerdeki hız testleriyle arasında benzer ilişkililer bulunmuştur. HDSAM'ın hız testleriyle arasında $p<.05$ ve $p<.001$ anlamlılık düzeylerinde küçük ilişkiler bulunmuştur. Bunun yanı sıra dikkat çeken bir bulgu HDSAM' in SPS alt testiyle negatif küçük (r=-.16) ve anlamlı bir ilişki göstermesidir. HDSAM ile PNM, ND ve SNT alt testleri birbirlerine benzer bir şekilde küçük düzeyde ve anlamlı ilişkiler $(\mathrm{rPNM}=.18, \mathrm{rND}=.21$ ve $\mathrm{rSNT}=.20, p<.001)$ bulunmuştur. Hız testlerinin korelasyonları incelendiğinde CAS 2 ölçeğine ait PCd, PNM, ND ve RA alt testlerinin kendi içinde ( $r=.48$ ile r=.59) arasında değişiklik göstermiştir. Bu alt testler içinde en büyük korelasyon katsayısı RA ile PNM alt testleri arasında anlamlı büyük ( $r=.59$ ) düzeyde ilişki, en düşük ilişki PNM ile PCd arasında anlamlı orta $(\mathrm{r}=.48)$ düzeyde ilişki olarak bulunmuştur. RIAS-2 ölçeğine ait SPS ile SNT arasında anlamlı, negatif küçük (r=-.21) düzeyde ilişki vardır.

\section{Tartışma}

Araştırma çerçevesinde ASİS SAM alt testinin puanlaması hıza göre düzenlenerek HDSAM ve $\operatorname{HDSAM}_{\text {(ap) }}$ puanlama sistemleri oluşturulmuştur. Bu puanlama düzenlemeleriyle CAS 2 ve RIAS2 zekâ ölçeklerinin hız alt testleri arasındaki ilişki ve HDSAM, HDSAM(ap)'ın geçerlik güvenirlik ölçümleri incelenmiştir.

Araştırma bulgularına göre SAM, HDSAM, $\operatorname{HDSAM}_{(\text {ap) }}$ 'n puanlama sistemleri arasındaki ilişkiler oldukça yüksek düzeyde bulunmuştur. Bu katılımcıların hıza dayalı ve hıza dayalı olmayan puanlama sistemlerinde maddeleri benzer sürede yanıtladıklarını göstermektedir. Bunun yanı sıra yüksek ilişki, Pallant’ın (2005) ifade ettiği üzere ölçümler arasındaki tutarlılık nedeniyle de ortaya çıkabilir. Çünkü SAM'ın maddeleri aynı kalıp sadece puanlama sistemi değiştirilmiştir. Bu yüzden yüksek ilişki katılımcıların SAM, HDSAM ve HDSAM' da benzer sürelerde muhakeme kurduğunu 
göstermektedir. Dolayısıyla hıza dayalı ve hıza dayalı olmayan ölçümler arasındaki benzerlik hızın doğası gereği kâğıt kalem testleriyle ölçülemeyeceğinin bir kanıtı olabilir. Bu yöntem yerine muhakeme hızı, ölçümlerin güvenirliğini ve geçerliğini artırmak için butonlu düzenekler ya da dokunmatik ekrana entegre bir şekilde sunulan hız testleriyle ölçülebilir.

Araştırmada HDSAM ve SAM ile ASİS endeks puanları orta düzeyde ilişkili ve aynı değerde bulunmuştur. Araştırmadan elde edilen bir diğer bulguya göre HDSAM ile SAM yüksek düzeyde ilişkilidir. Dolayısıyla araştırmanın iki bulgusu birbirini desteklemektedir. Çalışma belleğini temsil eden ASİS BKE puanları sözel alt testlerden, GPE puanları ise görsel alt testlerin etkisi altındadır. Bu görevlerdeki performanslar, bellek kapasitesindeki bireysel farklılıkları bir dereceye kadar yansitmaktadır. Örneğin, SAM muhakeme kurma yeteneğini içerir. Bununla birlikte SAM ve HDSAM endeks puanlarının görece küçük bir varyansını açıklamaktadır. Oysaki alanyazında hız performansının çalışma belleği görevleriyle görece yüksek ilişkili olduğu vurgulanmaktadır (Kail \& Salthouse, 1994). Ancak bu araştırmada HDSAM'ın bellek ve görsel performansı yeterince açılamadığı görülmektedir.

HDSAM ile ASIS'teki bellek ve görsel endeksleri temsil eden alt test görevlerinin yerine getirilmesi arasında katılımcıların yaşıyla ilişki kurulabilir. Nitekim işleme hızı teorisine göre hızın yaş değişkeniyle küresel bir eğim içerisinde ilişkili olduğu başka bir ifadeyle yetişkinliğe kadar artıp sonrasında düşüşe geçtiği bilinmektedir (Salthouse, 2000). Ancak araştırma katılımcılarının altı ile yedi yaş düzeyinde olması deneyim eksikliği yaratabilir ve hız performansını etkileyebilir (Goldhammer \& Entink, 2011). Buradan hareketle hıza dayalı testler öğrenme deneyimi eksikliği olan küçük yaş düzeyindeki katılımcılar üzerinde zaman baskısı kaygı yaratabilir. Nitekim mevcut araştırmada katılımcılar 58 madde içinden en fazla 28 maddeyi cevaplandırmıştır. Dolayısıyla bu kaygıya eşlik eden bilgi eksikliği, dikkat sorunları, motivasyon gibi değişkenler test puanları üzerinde önemli rol oynar. Bu nedenle katılımcıların hız testlerinde zaman kaygısını hissetmeden bilişsel performanslarını sergilemesi sağlanmalıdır.

Araştırma bulgularına göre SAM, HDSAM, HDSAM(ap)'dan elde edilen ölçümlerin iç tutarlılığ1 yüksektir. Öyle ki Pallant'ın (2005) önerdiği üzere ölçümlerin Cronbach Alfa değerlerinin .70'in üzerinde olması ideal kabul edilmektedir. Araştırma bulgusuyla benzer şekilde ASİS norm çalışmalarında ( $\mathrm{n}=4641$ ) SAM alt testi iç tutarlılığ $\alpha=.97$ düzeyinde yüksek bulunmuştur (Sak vd., 2016). Buna göre HDSAM, HDSAM(ap) ve SAM'ın yüksek düzeyde güvenilir olması ve önceki araştırmalarla desteklenmesi ölçeğe ilişkin yapısal tutarlılık kanıtının sağlandığının güçlü bir göstergesidir. Dolayısıyla araştırmanın çalışma grubundan elde edilen ölçümler güvenilirdir.

Araştırma bulgusuna göre SAM'ın puanlama sistemlerinden elde edilen puanlar bazı maddelerde anlamlı bir şekilde farklılaşmıştır. Madde 3, madde 17, madde 18 ve madde 27' de HDSAM lehine anlamlı, benzer şekilde madde 7 ve madde 17 ' de ise $\operatorname{HDSAM}_{(\text {ap) }}$ lehine anlamlı farklılık bulunmuştur. Bu maddeler katılımcıların SAM, HDSAM ve HDSAM(ap) test performanslarındaki farkın anlamlılığına ilişkin güven vermektedir. Nitekim zekâ ölçeklerinde maddeler, kolaydan zora madde güçlük düzeyine göre sıralanmaktadır. Bunun amacı, yanıtlayıcıların ölçeğin başlangıcında zor maddelerle karşılaştığında oluşabilecek endişe, heyecan gibi psikolojik faktörlerin test performansı üzerindeki etkisini azaltmaya çalışmaktır (Koğar, 2018). Dolayısıyla ölçeklerde madde güçlük düzeyine göre madde sıralaması yanıtlayıcıların test performansı açısından önem taşımaktadır. Bu 
bağlamda madde 3 ile madde 7'nin testin başlangıcında yer alması ve diğer maddelere görece kolay madde kategorisinde olması bu maddelerin daha hızlı cevaplanmasını sağlamıştır.

Araştırmanın bir diğer bulgusu madde toplam korelasyon ortalamalarına ilişkindir. SAM, $H_{D S A M}$ ve $\operatorname{HDSAM}_{(\text {ap })}$ için madde toplam korelasyon ortalaması en yüksek, HDSAM'da gözlenmiştir. Bu durumda HDSAM, SAM ve HDSAM(ap)' da görece muhakeme hızı orta düzeyde ayırt edicilik sağlamaktadır. HDSAM'a ilişkin bu ayırt edicilik katılımcıların görece daha hızlı muhakeme kurduğunu göstermektedir.

Araştırma kapsamında HDSAM ile CAS-2, RIAS 2 hız testleri arasındaki ilişki incelenmiştir. Buna göre HDSAM ile CAS 2 PNM, PCd, NA, RD ve RIAS-2 SPS, SNT testleri arasında küçük ilişki vardır. Erkuş'a (2012) göre bu ilişki ölçülmek istenen değişkenler birbiriyle uyumsuz olduğunda meydana gelmektedir. Ancak alanyazında zekâ ölçeklerinin hız testleri arasındaki korelasyon araştırmalarında benzer biçimde küçük düzeyde ilişkiler raporlanmıştır. Örneğin, RIAS-2' de SPS alt testiyle WISC-IV SS alt testi arasında küçük (r=-.06), SPS ile WISC-IV CA alt testi arasında küçük $(\mathrm{r}=-.17)$ düzeyde ilişki rapor edilmiştir. Öte yandan RIAS-2 SNT ile WISC-IV SS alt testi arasında $(\mathrm{r}=.25)$, RIAS-2 SPS ile WISC-IV CA alt testi arasında ( $\mathrm{r}=.29)$, SNT ile WSIC-IV şifre alt testi (CD) arasında (r=.14), SPS ile WSIC-IV CD alt testi arasında küçük ( $r=.08)$ düzeyde ilişki vardır (Reynolds \& Kamphaus, 2015). Mevcut araştırmaya göre RIAS-2 ile CAS 2 hız alt testleri arasında da küçük (rsps-PCd=.-23, rsPs-RA=.-28) ve orta ( $\mathrm{rSNT}-\mathrm{PCd}=.39$ ) düzeyde ilişki bulunmuştur. Hız alt testlerinde madde sayısı az ancak maddeye ait görev sayısı tamamlanamayacak kadar çoktur. Bu da madde sayısı azaldıkça maddeden alınan en düşük ve en yüksek puan arasındaki farkın azalmasına neden olur. Bu maddelerin homojenliğini işaret etmekle birlikte maddenin bilenle bilmeyeni ayırt etmesi güçleşir. Bu nedenle hem önceki araştırmalar hem de mevcut araştırma bulgularının doğruladığı üzere küçük ilişki beklenen bir sonuçtur. Bunun aksi bir sonuç WISC-IV ve WISC-V işleme hızı endeksleri arasında yüksek ilişki (r=.70) olarak rapor edilmiştir (Flanagan \& Alfonso, 2017). Ancak bu ölçeklerin hız testlerinin aynı görevlerden oluşmasından kaynaklanabilir.

CAS 2 ND, RA, PNM, RIAS-2 SPS, SNS alt testlerinde hızın yanında farklı bilişsel beceriler de işe koşulmaktadır. Bunlar algısal hız, odaklanmış dikkat, seçici dikkat, planlama, ilişki kurma, ifade edici dil becerisi ve psikomotor becerileri içermektedir. Bununla birlikte araştırma bulgularına göre anlamlı ilişkiler hız performansı üzerinde örtük değişkenlerin rolünü gösterir. Öyle ki Goldhammer \& Entink'in (2011) belirttiği gibi öğrenme düzeyi, deneyim hız performansını etkilemektedir. Buna testlerin dayandığı kuramsal yapı, test örneklemi, madde güçlük düzeyi, puan değeri ve madde tamamlama süresi eklenebilir. Alanyazında da vurgulandığı gibi hız testlerinin nasıl olması gerektiğine ilişkin bir uzlaşı olmamakla birlikte (Tulsky \& O'Brien, 2008) hızın çok yönlü yapısı nedeniyle uzlaşı aranması gerekli değildir. Ancak bu durum hız testlerinin çeşitliliğini sağlamakla birlikte korelasyon çalışmalarında sınırlı sayıda test yorumlamayı güçleştirmektedir. Bu nedenle hızın algı, işleme, psikomotor, karar, muhakeme hızı gibi diğer boyutlarını ölçen hız testlerinin geliştirilmesine ihtiyaç duyulmaktadır.

\section{Sonuç}

Hız testlerinin doğası gereği katılımcıların maddeleri hızlı bir şekilde yanıtlaması beklenir. Ancak tek başına maddenin yanıtlanması yeterli değildir. Önemli olan dikkat becerilerinin işe koşularak 
göreve ilişkin çıkarımlar yapılması ve doğru yanıtın verilmesidir. Bu bilişsel sürecin gerçekleştirilmesinde muhakeme yeteneği de etkin bir şekilde kullanılır (Gardner, 1993). Hız görevlerinin, gerek algı hızı gerek işleme hızı gerekse muhakeme hızına yönelik olması dikkat becerilerinden ve birbirinden nispeten bağımsız değildir. Ancak hız testlerinde asıl ölçülmek istenen hız faktörü daha baskındır. Bu yüzden bu araştırmada muhakeme hızı ölçülürken, CAS 2 ve RIAS-2 hız alt testlerinde algı ya da işleme hızı ölçülmektedir. Dolayısıyla HDSAM ile hız testleri arasındaki ilişki incelendiğinde zekâ ölçeklerindeki muhakeme hızı ile algı hızının test görevleri bakımından farklılaştı̆̆ını ve araştırmanın alanyazında hıza dayalı testlerle yapılan önceki araştırma bulgularıyla tutarlı olduğu vurgulanabilir.

\section{Kaynakça}

Bademci, V. (2011). Kuder-Richardson 20, Cronbach'in alfası, Hoyt'un varyans analizi, genellenirlik kuramı ve ölçüm güvenirliği üzerine bir çalışma. Dicle Üniversitesi Ziya Gökalp Eğitim Fakültesi Dergisi, 17, 173-193.

Ball, K. K., \& Vance, D. E. (2008). Everyday life applications and rehabilition of processing speed deficits: Aging as a model for clinical populations. In J. DeLuca and J. H. Kalmar (Eds.), Information processing speed in clinical populations (pp. 243-258). Taylor and Francis.

Çakmur, H. (2012). Araştırmalarda ölçme-güvenilirlik-geçerlilik. TAF Preventive Medicine Bulletin, 11(3), 339-344.

Cohen, J. (1988). Statistical power analysis for the behavioral sciences (2nd edition). Lawrence Erlbaum Associates.

Crocker, L., \& Algina, J. (2006). Introduction to classical and modern test theory. Wadsworth.

Dehn, M. J. (2014). Essentials of processing assessment (2nd edition). John Wiley and Sons.

Deluca, J., \& Chiaravalloti, N. D. (2004). Memory and learning in adults. In G. Goldstein, S. R. Beers, and M. Hersen (Eds.), Comprehensive handbook of psychological assessment: Intellectual and neuropsychological assessment (Vol:1, pp. 217 -236). John Wiley and Sons.

Diedenhofen, B., \& Musch, J. (2015). Cocor: A comprehensive solution for the statistical comparison of correlations. PLOS ONE, 10(4), 1-12.

Ekstrom, R. B., French, J. W., Harman, H. H., \& Dermen, D. (1976). Manual for Kit of Factor-Referenced Cognitive Tests. Educational Testing Service.

Erkuş, A. (2012). Psikolojide ölçme ve ölçek geliştirme. Pegem Akademi Yayınları.

Flanagan, D. P., \& Alfonso, V. C. (2017). Essentials of WISC-V assessment. John Wiley \& Sons.

Floyd, R. G., McGrew, K. S., \& Evans, J. J. (2008). The relative contributions of the Cattell-HornCarroll cognitive abilities in explaining writing achievement during childhood and adolescence. Psychology in the Schools, 45(2), 132-144.

Ford, D. Y. (2004). Intelligence testing and cultural diversity: Concerns, cautions and considerations. University of Connecticut.

Fry, A. F., \& Hale, S. (2000). Relationships among processing speed, working memory, and fluid intelligence in children. Biological Psychology, 54(1-3), 1-34.

Gardner, M.F. (1993). Test of auditory reasoning and processing skills (manuel). Academic Therapy Publication.

George, D., \& Mallery, P. (2010). SPSS for Windows step by step: A simple guide and reference, 17.0 update (10th Edition). Pearson.

Goldhammer, F., \& Entink, R. H. K. (2011). Speed of reasoning and its relation to reasoning ability. Intelligence, 39(2-3), 108-119. 
Kail, R. V. (2008). Speed of processing in childhood and adolescence: Nature, consequences, and implications for understanding atypical development. In J. DeLuca and J. H. Kalmar (Eds.), Information processing speed in clinical populations (pp. 101-123). Taylor and Francis.

Kail, R., \& Salthouse, T. A. (1994). Processing speed as a mental capacity. Acta Psychologica, 86(2-3), 199-225.

Karakoç, A. ve Dönmez, P. (2014). Ölçek geliştirme çalışmalarında temel ilkeler. Tıp Eğitimi Dünyası. 40(13), 39-49.

Koğar, H. (2018). Examining invariant item ordering using mokken scale analysis for polytomously scored items. Journal of Measurement and Evaluation in Education and Psychology, 9(4), 312325.

Kyllonen, P. C., \& Zu, J. (2016). Use of response time for measuring cognitive ability. Journal of Intelligence, 4(4), 14-42.

Moll, K., Göbel, S. M., Gooch, D., Landerl, K., \& Snowling, M. J. (2016). Cognitive risk factors for specific learning disorder: Processing speed, temporal processing, and working memory. Journal of Learning Disabilities, 49(3), 272-281.

Naglieri, J. A., Das, J. P., \& Goldstein, S. (2014). Cognitive assessment system second edition interpretive and technical manual. Pro-ed Inc.

Pallant, J. (2005). SPSS survival guide: A step by step guide to data analysis using SPSS for Windows (3rd edition). Open University Press.

Reynolds, C. R., \& Kamphaus, R. W. (2015). Reynolds Intellectual Assessment Scales- 2 2nd edition. Psychological Assessment Resources.

Sak, U., Ayas, B., Bal-Sezerel, B., Tokmak, F., Özdemir, N. N., Demirel-Gürbüz, Ş. ve Öpengin, E. (2016). Anadolu-Sak Zekâ Ölçeği: ASİS uygulayıcı kitabı. Anadolu Üniversitesi ÜYEP Merkezi.

Salthouse, T. A. (2000). Aging and measures of processing speed. Biological Psychology, 54(1-3), 3554.

Schrank, F. A., McGrew, K. S., \& Mather, N. (2014). Woodcock-Johnson IV tests of cognitive abilities. Riverside.

Schneider, W. J., \& McGrew, K. S. (2018). The Cattell-Horn-Carroll theory of cognitive abilities. In D. P. Flanagan and E. M. McDonough (Eds.), Contemporary intellectual assessment: Theories, tests, and issues (4th edition, pp.73-163). Guilford Press.

Schubert, A.-L., Hagemann, D., Voss, A., Schankin, A., \& Bergmann, K. (2015). Decomposing the relationship between mental speed and mental abilities. Intelligence, 51, 28-46.

Özdamar, K. (2004). Paket programlar ile istatistiksel veri analizi. Kaan Kitabevi.

Tulsky, D. S., \& O'Brien, A. R. (2008). The history of processing speed and its relationship to intelligence. In J. DeLuca and J. H. Kalmar (Eds.), Information processing speed in clinical populations (pp. 1-28). Taylor and Francis.

Vukovic, R. K., \& Siegel, L. S. (2010). Academic and cognitive characteristics of persistent mathematics difficulty from first through fourth grade. Learning Disabilities Research and Practice, 25(1), 25-38.

Wechsler, D. (1991). Wechsler intelligence scale for children manual (3rd edition). The Psychological Corporation.

Wechsler, D. (2014). Wechsler intelligence scale for children (5th edition, WISC-VCDN). Pearson.

Wilhelm, O., \& Schulze, R. (2002). The relation of speeded and unspeeded reasoning with mental speed. Intelligence, 30(6), 537-554. 